\title{
Significados latentes na fotografia em turismo: o caso do turismo negro na Costa Morte (Galiza)
}

\author{
Antonio Azevedo* \\ Universidade do Minho (Portugal)
}

\begin{abstract}
Resumo: Até que ponto uma fotografia pode ser uma representação da identidade de um lugar, contagiar emoções, simular/ emular experiências e motivar a visita ao destino? Este estudo procura explorar o fascínio (gaze) pela imagem, influência da interpretação da paisagem, da perceção autenticidade, da densidade psicológica associada a imagens de turismo negro? Que elementos e símbolos são possíveis de forma explícita ou latente? Qual o papel do turista na co-criação da imagem do destino?

Este estudo tem como ponto de partida e unidade de análise o património imaterial e a "aura" emanada por diversos lugares e paisagens da Costa da Morte na Galiza condimentadas pelas lendas e mitologia de um passado histórico rico em acontecimentos. Usando uma abordagem metodológica que incluiu a seleção e análise qualitativa de fotografias, documentários e livros, a observação direta, a netnografia passiva e photo elicitation (elicitação de pensamentos a partir da fotografia), foram propostos diversos elementos ou categorias de classificação de conteúdos latentes.
\end{abstract}

Palavras-chave: significados latentes; gaze; turismo negro; Costa da Morte (Galiza); experiências; photo-elicitation (elicitação de pensamentos a partir da fotografia),

Latent content in tourism photos: the case of dark tourism in Costa Morte (Galiza)

Abstract: To what extent can a photograph be a representation of the identity of a place, spread emotions, simulate / emulate experiences and motivate the visit to the destination? This study seeks to explore the fascination (gaze), the influence of landscape interpretation, the perception of authenticity, the psychological density associated with images of black tourism? What elements and symbols are possible in an explicit or latent way? What is the role of the tourist in the co-creation of the image of destiny? This study has as its starting point and unit of analysis the intangible heritage and the "aura" emanated by various places and landscapes of the Costa da Morte (Coast of Death) in Galicia spiced by the legends and mythology of a rich in events historical past. Using a methodological approach that included qualitative selection and analysis of photographs, documentaries and books, direct observation, passive netnography and photo elicitation several latent content elements or classification categories were proposed.

Keywords: latent content; gaze; dark tourism; Coast of the Death (Galicia); experiences; photo-elicitation.

\section{Introdução}

A atração por lugares e eventos associados à morte, tragédias individuais ou catástrofes coletivas têm sido amplamente discutidas por diversos autores (Stone, 2005, 2009; Sharpley, 2009; Podoshen, 2013). O conceito de turismo negro ${ }^{1}$ (dark tourism ou thanatourism) foi definido por Foley and Lennon (1996, p.198) como a "apresentação e o consumo (pelos visitantes) de lugares de morte e desastre reais ou mercantilizados".

Stone (2006) propôs a existência de várias camadas dentro do turismo negro, que o autor definiu como estágios, que gradualmente podem ser simbolicamente associados a uma cor mais clara até à mais

Professor Auxiliar, Departamento de Gestão, Escola de Economia e Gestão da Universidade do Minho, Braga, Portugal; E-mail: antonioa@eeg.uminho.pt 
escura. A forma mais escura da definição relaciona-se com lugares e eventos, onde as pessoas realmente sofreram e morreram, como por exemplo, o campo da morte em Auschwitz. Estes locais mais escuros são fortemente influenciados por uma ideologia política e têm fins educacionais. Pode-se dizer que estes locais são autênticos, especialmente quando o local ou sítio ainda está localizado nas instalações originais. O critério para a classificação no lado mais leve do turismo negro ocorre quando o local é apenas associado com a morte e sofrimento, como por exemplo, os itinerários baseados na temática do terror organizadas nas cidades.

Alternativamente, Sharpley (2009) propôs uma grelha com quatro quadrantes cujos eixos são a forma como o interesse (explicito ou implícito) pela morte é expresso em combinação com o grau de orientação da oferta para o fascínio do turista (intencional ou acidental). Stone \& Sharpley (2008, p.586) desenvolveram também um modelo que procura conceptualizar o turismo negro, como a oportunidade de confrontar com "momentos de mortalidade", a uma distância e ambiente percebidos como seguros, permitindo assim a "neutralização social" e "des-sequestração" da morte e a sua reconceptualização.

Conforme referiu recentemente Podoshen (2013), ainda poucos estudos se dedicaram a estudar os antecedentes, as motivações, os mecanismos psicológicos e os fatores push/pull, que influenciam a decisão pré-visita, e os comportamentos durante a experiência da visita e no momento pós-visita (fidelidade e word-of-mouth).

Os fatores push levam os turistas a procurar atividades para satisfazer as suas necessidades, e são identificados como motivos internos ou relacionados com a procura. Assim, são referidos por Podoshen (2013) alguns fatores individuais ou motivadores como por exemplo:

I. Curiosidade ou voyeurismo (Cole, 1999);

II. Procura de sensações fortes, de aventura, escape a uma realidade distópica (Podoshen et al 2015) ou novas experiencias (Rojek,1997);

III.Schadenfreude, termo alemão para designar para designar o sentimento de alegria ou satisfação perante o dano ou infortúnio de um terceiro. (Sharpley, 2009);

IV. Desejo de conexão com o passado;

V. A necessidade de confirmar a realidade por detrás do mito ou lenda, designada na literatura por "comparação entre paisagens" (Podoshen, 2013);

Os fatores pull estão relacionados com a oferta e, resultam das atividades de marketing levadas a cabo pelos operadores turísticos do destino (Lennon and Foley, 2000). Por exemplo, segundo Sharpley \& Stone (2009) e Moscardo \& Ballantine (2008), a interpretação é uma componente chave, que para além de informar deverá atuar de forma provocadora sobre as emoções dando vida aos lugares, aumentando o nível de autenticidade (Tilden, 1977). Por isso, se os operadores e os destinos disponibilizarem recursos humanos e tecnológicos que proporcionem uma melhor informação e interpretação, isso pode ser um elemento diferenciador da experiência.

O processo de escolha do destino turístico, atualmente, é influenciado por diversos estímulos e, em particular, pelo fascínio (gaze) por imagens das atividades e experiências de turismo negro obtidas por diversas fontes: filmes, documentários, livros; material publicitário dos operadores turísticos; do word-of-mouth eletrónico partilhado nas redes sociais (Henderson, 1991; Xiang \& Gretzel, 2010; Hsu \& Song, 2014; Llodrà-Riera et al., 2015; Van-House, 2009; Hosany \& Prayag, 2013).

Por outro lado, Kim \& Stepchenkova (2015) destacaram a importância do estudo dos efeitos dos conteúdos explícitos (elementos e sinais que podem ser objetivamente interpretados pelo seu "valor facial") e, dos conteúdos latentes nas fotografias, constituídos pelos sinais implícitos que podem ser deduzidos cognitivamente, lidos nas entrelinhas, ou simplesmente, resultam de impressões ou significados de leitura subjetiva (Riffe, Lacy \& Fico, 2005). Será importante considerar neste contexto o conceito de autenticidade, que Rickly-Boyd (2012) analisou teoricamente numa abordagem simbólica, em que o turista experiencia a "aura" do lugar como um fragmento de espaço-tempo. Muitas vezes os turistas referem a procura da autenticidade como um dos fatores de motivação e critério de escolha do destino, ou das atividades em que participam.

Conforme referiu Berger (2004, p.6, citado por Ribeiro), os símbolos em turismo são "mitos e rituais camuflados, simplificações de desejos ancestrais e cosmogenias". Ainda Özdemir (2010, citado por Hsu \& Song, 2014), afirmou que uma atmosfera ou um determinado estado de espirito do destino pode ser registado numa fotografia. 
Este estudo procura identificar os argumentos chave que são fatores de atração para o turista (Min, Martin \& Jung, 2013) e os elementos imagéticos que inspiram fantasias, emoções, conduzindo a diferentes tipologias de experiencias percebidas.

Surgem então algumas questões de pesquisa sobre as quais o autor pretende discutir e refletir:

I. Até que ponto uma fotografia pode ser uma representação da aura, da identidade de um lugar e despertar emoções ou simular/ emular experiências?

II. O que explica o fascínio (gaze) por essas imagens?

III.Qual o papel da interpretação dessas imagens na motivação para visitar o destino?

IV. Será possível descodificar em elementos, a paisagem, a densidade psicológica associada a atividades relacionadas com o turismo negro?

V. Qual o papel catalisador das lendas e da mitologia?

VI. Qual a importância da perceção da autenticidade?

VII. Qual o papel do turista na co-criação da imagem do destino?

Este estudo tem, como ponto de partida e unidade de análise, o património imaterial e a "aura" emanada por diversos lugares e paisagens da Costa da Morte na Galiza. A imagem deste destino tem uma componente bastante forte associada ao turismo negro, que resulta sobretudo de uma elevada taxa de naufrágios e situações trágicas ocorridas ao longo da história nesta costa, com uma morfologia propícia a acidentes marítimos (Mouzo, 2014; Cortizo, 2016). A estes desastres podemos adicionar os mitos e lendas, que remontam desde a pré-história, e posteriormente no império Romano. Estes consideravam esta zona e, em particular Finisterra, como o "fim da terra" e, portanto, o início de um mundo desconhecido. Estão reunidos portanto, os ingredientes para uma atmosfera, que estimula a imaginação do turista, em particular, daqueles que procuram novas experiencias e sensações.

Dado o simbolismo associado à Costa da Morte, cada turista pode construir a sua própria experiencia autêntica inspirados na densidade psicológica que a história e a paisagem desperta.

Por vezes a realidade objetiva é sobreposta pelo "imaginário" do turista, definido por Salazar (2012, p.864) como uma "composição de representações socialmente transmitida que interage com a imaginação ou fantasia individual e é usada como instrumento de criação de significados e moldagem da realidade".

De acordo com o mesmo autor, a única forma de estudar estes imaginários de natureza intangível, é através do estudo de imagens e discursos, que transparecem nos filmes, documentários, fotografias, postais, blogs de viagens, exposições, feiras, brochuras turísticas, revistas, literatura e na publicidade.

\section{Revisão da literatura}

\subsection{Curiosidade, procura de sensações novas, excitação, o fascínio pela morte e o contágio emocional}

A literatura sugere que a curiosidade humana sobre a atrocidade é insaciável e que as pessoas são motivadas por empatia, emoção e outros estímulos psicológicos. Como salientaram Lennon \& Foley (2000), o horror e a morte tornaram-se mercadorias comercializáveis. Até no nosso quotidiano, conseguimos ver o poder da curiosidade quando acontece um acidente de viação e se forma uma multidão de espectadores. Também os nossos antepassados revelavam um interesse forte por eventos, ou sítios que estivessem relacionados com morte ou sofrimento, nomeadamente são exemplos destes eventos, a lutas dos gladiadores ou execuções públicas.

Para entender a curiosidade como motivadora, é necessário olhar para a investigação nos domínios da psicologia e sociologia (Montgomery, 1952). Por exemplo, Berlyne (1950, 1966) observou que estímulos em repetição fazem, gradualmente, perder o poder de aumentar a excitação, no entanto, a novidade aumentou o comportamento exploratório. Cohen (1974) evidenciou que a novidade é um elemento essencial das experiências em turismo, no entanto, ele também observou que muitos turistas preferiram uma certa familiaridade, a fim de apreciarem a novidade das suas experiências.

A novidade pode ser decomposta em quatro dimensões (Kelly, 1991): a mudança de rotina, escape, excitação e aventura. A mudança de rotina inclui também uma mudança de ambiente, do ambiente habitual do turista, enquanto escape como uma distração temporária da realidade, do tédio provocado pela rotina, ou uma oportunidade para escapar dos problemas da vida (McIntosh \& Goeldner, 1986). Para além disso, os turistas procuram conhecer novas pessoas e novas experiencias sociais.

Por outro lado, Hornby (1974) definiu excitação como uma experiência, na qual a emoção é o elemento essencial. Vários estudos encontraram que as pessoas procuram experimentar coisas novas, mesmo 
com algum risco, mas sobretudo com imprevisibilidade. A aventura é definida como uma experiência emocionante, obtida através de acontecimentos estranhos e incomuns (Mayo \& Jarvis, 1981).

No turismo negro, os dois conceitos complementam-se por isso um destino deve introduzir constantemente elementos de novidade e aventura de forma a potenciar as sensações de excitação no turista.

Para Tarlow (2005), existem quatro emoções básicas que interagem com a psicologia do amante de turismo negro: insegurança, a gratidão, humildade e superioridade. Estas emoções podem ainda associarem-se a sentimentos de coletivismo, tristeza, complacência, vitória, pena ou romantismo. Quão mais próxima a experiência, maior será a ligação entre aquele que sofreu nesse local e este visitante.

Porém, Moutinho (2000) afirma que, a nova geração de viajantes procura novos tipos de emoções, procura encontrar-se a si próprio e compreender outras culturas através da sua 'aura psicológica'. Isto significa que, querem sentir mais de perto o imaginário de cada país que visitam, tendo a necessidade de se verem envolvidos em ação, mesmo sendo esta perigosa. Este tipo de experiencias levanta questões profundas dentro do visitante, pois abre uma hipótese de saber mais acerca do sofrimento que tomou lugar naquele sítio, providenciando-lhe aventura, educação, emoção e inclusão no imaginário desse país ou local. Também Lin et al (2014) verificaram que a personalidade do turista pode interagir com as emoções em particular com o medo, a tristeza e o nojo.

Por outro lado, de acordo com a teoria da simulação de Gordon \& Cruz (2002), citados por Podoshen (2013), o individuo pode gerar em si próprio um estado de espirito de forma a replicar ou simular o estado de espirito de outros, no presente ou no passado. Ainda segundo Preston \& de Waal (2002), a observação ou imaginação de um outro individuo, num estado emocional específico, automaticamente ativa a imitação desse estado com uma resposta psicossomática e autónoma. Assim, Hatfield, Cacioppo and Rapson (1992) definiram contágio emocional como uma emoção que é transmitida de uma pessoa para outra de forma inconsciente e mais rápida (Coplan, 2006).

Recentemente, Podoshen et al (2015) analisam também o conceito de distopia (o contrário de utopia) como uma visão coletiva (negativa) sobre um futuro alternativo para a sociedade. Este sentimento pode emergir no visitante, quando confrontado com o que de mau e perverso o ser humano é capaz. Por outro lado, os autores referem que o turismo negro pode ser um escape a um quotidiano distópico.

As nossas memórias são essenciais para que haja uma ligação entre o nosso passado e o futuro. É exatamente isto que as atrações de turismo negro permitem aos indivíduos: reviver o passado. Os turistas procuram experiencias emocionais que possibilitem a recriação de histórias de tragédias ocorridas, de forma a estar em contacto direto, seja este real ou fictício, com o passado da sociedade atual.

\subsection{Fatores pull: cultura, história, santificação e o papel dos meios de comunicação social}

Segundo Foote (1997), as atitudes relacionadas com tragedia e violência estão ligadas a valores culturais. Quando um local está relacionado com um acontecimento trágico ou violento, um de quatro resultados acontecem: santificação, designação, retificação, ou obliteração.

Os motivos mais comuns para a santificação são honrar mártires, heróis caídos, grandes líderes ou a perda de sentido de comunidade. O processo envolve a criação de um lugar sagrado, frequentemente identificado por um marcador durável, como uma estátua, construção, monumento ou memorial (Foote, 1997). A santificação também envolve alguma forma de consagração formal, normalmente uma cerimónia explicando a história e o significado do local. Como exemplo, pode-se indicar o memorial do Holocausto em Berlim, a casa de Anne Frank em Amesterdão, entre outros.

Muitas vezes os turistas não sentem fascínio por locais e eventos relacionados com morte e desastre, estão apenas interessados na história. Apesar do interesse por história ser considerado um importante meio de motivação, os locais de turismo negro têm ainda dificuldades em associar história a locais negros. Têm dificuldade em escolher quais aspetos devem contar aos visitantes, se os aspetos positivos da história, se os aspetos negativos relacionados com o mal e com o macabro (Lennon \& Foley, 2000).

Segundo Stone (2006) a atração está dependente de vários fatores entre os quais: a localização; os itens materiais (tem que estar ligados às circunstancias em que as mortes ocorreram para tornar a experiencia o mais real possível); a informação e exatidão dos factos apresentados nos locais de atração. Debord (1994) salientou que muitas vezes se recorre ao "espetáculo" para criar curiosidade nos visitantes. Lennon e Foley (2000) reconheceram que, alguns locais de turismo negro se tornaram famosos e notórios, introduzindo elementos espetaculares para recriarem o ambiente e, sem que haja muitas vezes justificação e documentação histórica para fazer a exibição de tais objetos perturbadores. Sem interpretação adequada, a exposição desses objetos pode tornar-se espetáculo. Ainda é de considerar que a literatura e filmes que relatam histórias verídicas de sobreviventes despertam o interesse dos 
indivíduos a viajar para fomentar o seu conhecimento histórico, compreensão pelos fenómenos. Os locais de turismo negro promovem a sua missão educacional junto das gerações vindouras.

Segundo Stone (2006), os media tornaram-se um dos maiores mediadores da morte, não só da forma como divulgam a informação sobre a mesma, mas também, da forma como conseguem influenciar a nossa interpretação sobre a mesma. A forma como os media conseguem passar noticias e imagens sobre a morte, sofrimento e tragédias incita a visitar locais onde estes aconteceram. Ainda segundo Reijnders (2011), os turistas têm tendência a comparar a paisagem que estão a visitar com a imagem que criaram previamente nas suas mentes baseadas nos estímulos de livros e filmes ou material publicitário de operadores turísticos (Crouch, Jackson \& Thompson, 2005).

\section{Elementos de turismo negro na Costa da Morte}

Como unidade de análise de aplicação dos conceitos discutidos na secção anterior optou-se por selecionar um conjunto de imagens de lugares e paisagens da Costa da Morte na Galiza publicadas em nos websites oficiais que promovem o destino, ou publicadas por turistas nas redes sociais. Esta costa acidentada, geograficamente com limites indefinidos, que podem começar nas ilhas Sisargas ou mais a norte desde o Farol da Torre de Hércules na Corunha, até ao Farol do cabo de Finisterra, ou um pouco mais a sul na ria Muros (Garcia, 2013).

O turista que visita a Costa da Morte (CdM) tem várias motivações associadas a diferentes fatores de atração e produtos turísticos, que esta região proporciona: turismo de natureza (paisagem), sol e mar (praias e ilhas), turismo religioso (Caminho de Santiago), o turismo marinheiro (rota dos faróis, pesca artesanal), turismo náutico e, por último, o segmento analisado neste estudo - o turismo negro associado aos 643 naufrágios, registrados por Mouzo (2014), e os 5984 mortos e desaparecidos e respetivos destroços e espólio saqueados.

O caso que despoleta o uso desta toponímia em 1904 pelo jornal El Noroeste e, o consequente mito romântico, ocorreu em 10 de novembro de 1898 (Garcia, 2013). O navio inglês "HMS The Serpent" chocou contra as rochas dos Bois e, dos 175 tripulantes apenas três sobreviveram. O cemitério dos "Ingleses" é a evidência tangível dessa tragédia (Cela, 2001). Curiosamente, segundo afirmaram Castro \& Rodriguez (2009), pode ter sido a visibilidade mediática em tudo o mundo do desastre ambiental provocado pela rutura do petroleiro Prestige em novembro de 2002, que pode estar na origem da recuperação do turismo e na duplicação das unidades hoteleiras nos seis anos após o desastre.

Destaca-se também aqui o artigo de Garcia (2013), que combinou diversas fontes históricas e literárias (Richard Ford, George Borrow, Jules Michelet, Rosalía de Castro, Emilia Pardo Bazán, Fernando Gallego de Chaves y José Mas) para justificar a designação "Costa da Morte".

O escritor premiado com o Nobel, Camilo José Cela (2001) narra, de forma sublime e humorística, o balanço dos naufrágios ocorridos na Costa da Morte, num caldo de cultura onde se cruzam dezenas de personagens como: sacristãos, lobisomens, fantasmas, caçadores de baleias, curandeiras, suicidas, carpideiras, virgens martirizadas, sereias, bruxas e as suas mesinhas e receitas gastronómicas.

$\mathrm{Na}$ literatura podem-se, portanto, identificar como categorias, ou elementos ingredientes do medo cénico, que as paisagens e as fotografias selecionadas evidenciam:

1. Os temporais, as ondas gigantes que atraem os surfistas, a fúria do mar revolto contra a costa escarpada e as ilhas.

2. Os faróis, que constituem a rota "Camiño dos Faros" (www.caminodosfaros.com) (Blanco, 2014);

3. Os naufrágios relatados por Mouzo (2014);

4. As estórias associadas aos sobreviventes, relatadas ao pormenor por Cela (2001, p.61), que inclui, por exemplo, avistamentos de navios "fantasma", como o El Compostelano, que, abandonado pela tripulação, andou à deriva, mas alegadamente guiado por um gato, conseguiu subir o rio de Ponteceso, chegando a Telleria, após uma manobra de elevada perícia;

5. Os avistamentos de sereias e monstros marinhos;

6. As rochas com formas orgânicas, como, por exemplo, a "Piedra-del-Oso" em forma de urso, outras pedras com poderes curativos, nomeadamente, os enigmas das pedras junto ao Santuário da Barca de Muxia; ou ainda os altares de fecundidade;

7. As lendas de cidades e civilizações submergidas como "Dugium Duio a capital dos nérios" (Cela, 2001, p.12);

8. Os cemitérios, nomeadamente, o Cemitério dos Ingleses, o cemitério de Laxe ("do mar vê-se muito bem o cemitério"; Cela, 2001, p.62) 
9. As cruzes memoriais dos locais dos naufrágios mais emblemáticos;

10. As portas do inferno: "cuevas" e "furnas";

11. As atividades de pirataria negra ou rituais macabros no saque dos espólios, referenciados no documentário da TVE que, segundo Garcia (2013, p.272), não tem fundamentação histórica e são romantismos ficcionados com origem noutras regiões ${ }^{2}$.

12. A distopia, que é simbolicamente retratada com elevada criatividade na galardoada curta-metragem de Eduardo Brito de 2016, "Penumbria" http://www.eduardobrito.pt/, que descreve uma história ficcionada de uma cidade abandonada e inabitável: "De solos áridos, mares revoltados e clima violento, ficou a dever o seu nome à sombra e à nebulosidade quase permanentes. Até que um dia, os seus habitantes decidiram entregá-la ao tempo";

13. A "morriña", que em galego significa uma tristeza, nostalgia ou saudade por estar longe da terra e da família.

Como pano de fundo, ainda podem-se considerar a presença latente de outros elementos menos negros como a influência da mitologia Celta, os mitos e lendas, com origens na cultura da Galiza (Bouzas \& Domelo, 2000), o obscurantismo, bruxaria e outros rituais, dos quais se destaca a lenda da "Santa Compaña". Ou ainda, embora não exatamente relacionados com a paisagem marítima, mas num contexto mais largo, devem-se acrescentar também as rochas com petróglifos, ou as formações rochosas com formas humanas dos "bosques petrificados".

Também devemos lembrar as diversas peregrinações, de caracter religioso ou pagão, de que são exemplos a peregrinação a San Andrés de Teixido, ou a peregrinação a Finisterra, como um espaço mítico analisado por Herrero (2009) que remonta à pré-história e que, segundo Adrião (2011, p.228), resulta do posicionamento num ponto telúrico das linhas de força eletromagnéticas do planeta, também designado por "lugar de poder" ("power spot").

\section{Metodologia}

Neste estudo foram adotadas algumas abordagens qualitativas que são frequentemente usadas neste tipo de estudos (Podoshen, 2013):

I. observação ativa e não ativa do investigador como participante (Bryman, 2008);

II. netnografia passiva (Kozinets, 2010) na qual o investigador entra nas comunidades online como observador (Hsu, Dehuang \& Woodside, 2009; Podoshen \& Hunt, 2011), nomeadamente a página de facebook Costa da Morte Galicia - https://www.facebook.com/CostaDaMorteGalicia/?fref=ts, com mais de 10000 seguidores;

III.análise qualitativa de conteúdos (Bryman, 2008), que inclui a análise de documentos escritos, filmes e documentários (Belk, 2011), como por exemplo, o documentário de 2013 de Lois Patiño (http://www.zeitunfilms.com/en/cdm/index), ou livros, como "Madera de Boj" (Madeira de Buxo) de Camilo José Cela, contribuem para a construção de um imaginário da Costa da Morte;

IV. photo elicitation, uma metodologia descrita por Matteucci (2013) e inspirada no protocolo de Dempsey \& Tucker (1994), no qual os investigadores selecionam imagens para ser analisadas e interpretadas;

V. A visibilidade e reputação online da Costa da Morte estudada por Rial (2014).

A lista das fontes analisadas é a seguinte:

I. Trailer do Filme de Ignacio Vilar, "Sicixia", estreado em Novembro de 2016;

II. Filme/Documentário de Lois Patiño "Costa da morte", 2013: http://www.loispatino.com/Costa-da-morte; https://youtu.be/m1AgkWmJY4Q

III.Documentário da RTVE, 2011 - “07 - El mundo más allá del fin del mundo (A Coruña)” https:// youtu.be/fN-Z9GE7DH4

IV. Documentário da RTVE, 2011 "08 - Pazos, Señores, Reyes y Brujas (A Coruña y Lugo) https:// youtu.be/aO45UdXaovk

Por outro lado, Hunter $(2008,2010)$ propôs um sistema de classificação de fotografias de turismo em 16 categorias com base no objeto fotografado combinado com o tipo de sujeito (sem pessoas, o anfitrião apenas, o turista apenas e ambos turista e anfitrião). Seguindo as regras da análise de conteúdos, 
nomeadamente a objetividade, a sistematização, a amostragem e a fiabilidade (Kolbe \& Burnett, 1991), pode-se ver na Tabela 1 as categorias selecionadas.

\section{Tabela 1- Categorias de fotos selecionadas}

\begin{tabular}{lll}
\hline 1-Faróis & Foto 1 e 2-Punta Roncudo & Foto 3 e 4-Cabo Vilan \\
\hline 2-Temporal/ Tormenta & Foto 5- Muxia & Foto 6- Camariñas \\
\hline 3-Naufrágio & Foto 7- Prima (Laxe) & Foto 8- Prestige \\
\hline 4-Cemitério & Foto 9 e 10- Laxe & $\begin{array}{l}\text { Foto 11- Cemitério Ingleses e Foto 12- Santa } \\
\text { Mariña }\end{array}$ \\
\hline 5-Cruzes memoriais & Foto 13- Punta Roncudo & Foto 14- Punta Roncudo \\
\hline 6-Mitologia & Foto 15- Polvo (Corunha) & Foto 16- Sereia (Isla Salvora) \\
\hline 7-Distopia & $\begin{array}{l}\text { Foto 17- "Costa da Morte" de } \\
\text { Lois Patiño }\end{array}$ & Foto 18- "Penumbria" de Eduardo Brito \\
\hline 8-Fenómenos Celestes & Foto 19- Via lactea (Cabo Vilan) & Foto 20-Alinhamento planetas (Ihas Cies) \\
\hline & &
\end{tabular}

Figura 1 - Farol de Punta Runcudo (Fotos 1 e 2).
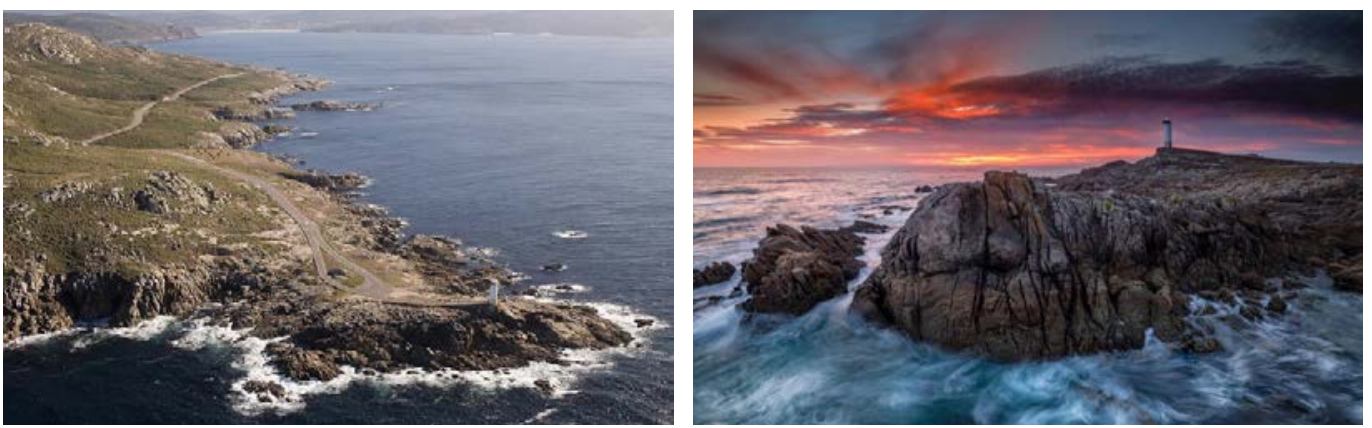

Fonte: Foto esquerda- http://www.turismo.gal/ria-de-corme-e-laxe?langId=es ES; Foto direita- autoria de @ chenchomendoza; publicado em https://www.facebook.com/CostaDaMorteGalicia/photos/a.42918383045906 3.99343.375313045846142/1226696367374468/?type=3\&theater)

Figura 2 - Farol de Cabo Vilan (Fotos 3 e 4).
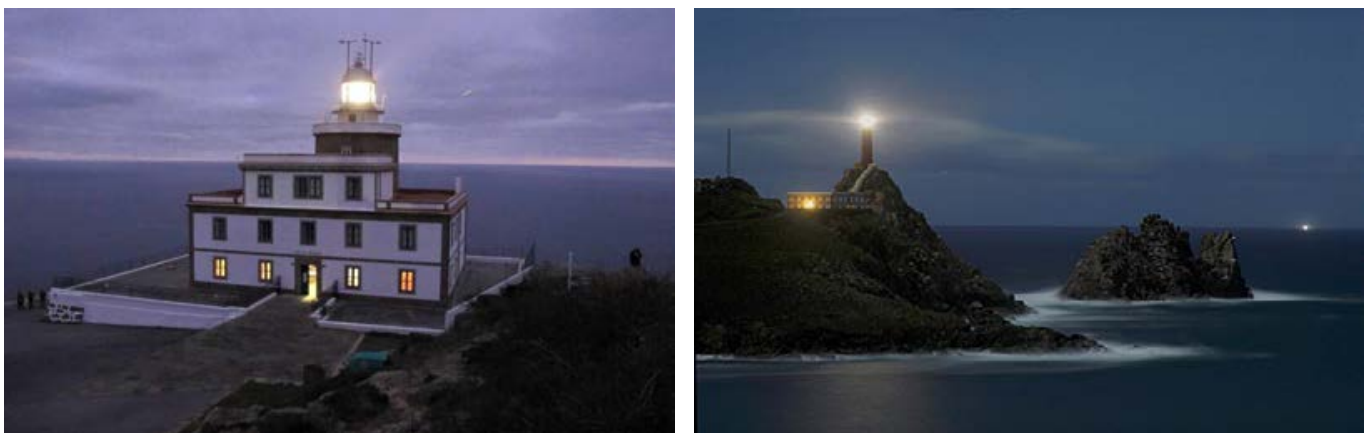

Fonte: Foto esquerda- de Eduardo Vidal (@eduvidalc), publicado em https://www.facebook.com/CostaDaMorteGalicia/photos/a.429183830459063.99343.375313045846142/1163761247001314/?type=3\&theater; Foto direita- http://www.deviajeporgalicia.com/wp-content/uploads/Faro-Cabo-Vilano1.jpg) 
Figura 3- Temporais, ondas gigantes em Muxia e Camariñas (Fotos 5 e 6).
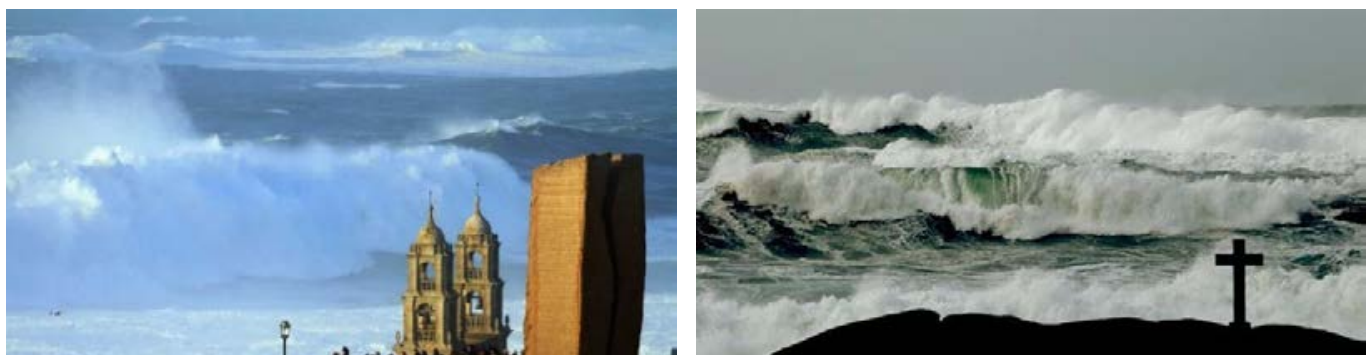

Fonte: Foto direita: http://www.teinteresa.es/espana/tiempo/Costa-Morte-municipio-corunes-Camarinas 1 1082301909.html; Foto esquerda: http://www.caminodosfaros.com/en/lighthouse-of-muxia/)

\section{Discussão e análise dos conteúdos latentes}

As fotos 1 a 4 das Figuras 1 e 2 pertencem à categoria de "faróis", lugares de refúgio, tranquilidade e solidão, que enfrentam as tempestades com a missão nobre de guiar os marinheiros na noite (Blanco, 2014). Os faróis encerram diversos significados e mistérios aos quais não é alheia a silhueta fálica que contrasta na paisagem natural. O farol do Cabo Vilan (Figura 2) está aberto ao público e a praia da Arneliña permite o enquadramento fotográfico perfeito. A análise do conteúdo latente, nesta categoria, automaticamente suscita a imaginação das consequências da não existência de faróis, ou relembra as lendas de pirataria negra, segundo as quais, alegadamente, algumas populações locais, motivadas pela ganancia do saque, provocariam de forma criminosa os naufrágios através da utilização de vacas com lanternas, que enganariam as embarcações nos dias de tempestade.

As fotos 5 e 6 da Figura 3 foram publicadas na página facebook "Costa da Morte Galicia" no âmbito do estudo de Rial \& Azevedo (2016) e, nos comentários às fotos, verificou-se um despertar de diversas das emoções e pensamentos que oscilavam entre o profano e o religioso: JB- "Pánico sabiendo lo que ha sucedido en las piedras y la iglesia"; DM-"El respeto que le debemos al magnifico mar que tenemos!!!"; CH- "Belleza. O mar na sua bravura e visto desde a distancia correcta é beleza pura"; IL- "Maravilloso espectaculo de fuerza y poder del mar"; SL- "Medo. pero o mar enfadase. Dios enfadase e non me estraña, somos moi egoistas"; NC- "Emocion, sentimiento, respeto por ese mar inmenso"; ER-"Sentir o salitre na cara...non ten precio!!!”.

Há, portanto, uma atração pelas ondas gigantes, por ouvir o ruido das massas de água que leva dezenas de curiosos a correrem riscos para assistir a este espetáculo da ciclogénese, que ocorre com maior frequência no inverno nos dias de lua cheia ou lua nova.

Como consequência das tempestades, ocorrem os naufrágios e, com eles, os sinais visíveis dos seus impactos na paisagem (ver Figura 4), como os destroços do Prima, encalhado ou ainda, a poluição ambientar com a cor negra, literalmente a significar a morte de seres vivos do ecossistema marinho (foto 8). Enquanto os destroços submergidos podem significar tesouros e riquezas, as montanhas de ferrugem à superfície simbolizam o fracasso e a decadência lembrando fim do ciclo da vida e a distopia destes lugares.

\section{Figura 4- Naufrágios: O Prima encalhado na praia de Riera (Foto 7) e o desastre do petroleiro Prestige (Foto 8).}
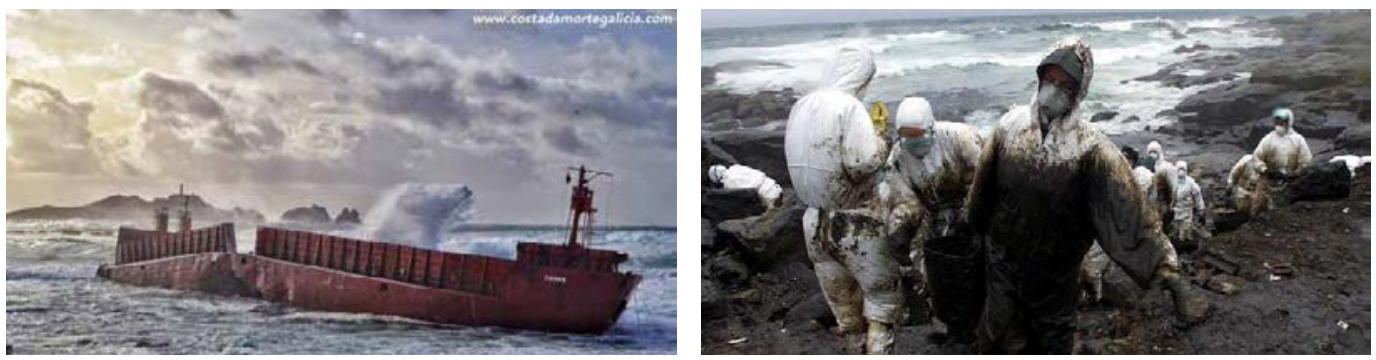

Fonte : (foto esquerda-http://costadamortegalicia.com/informacion/naufragios/; Foto direita- http://blogs. lavozdegalicia.es/javiersanz/tag/seguridad-maritima/) 
Figura 5- Cemitério de Laxe (Fotos 9 e 10).
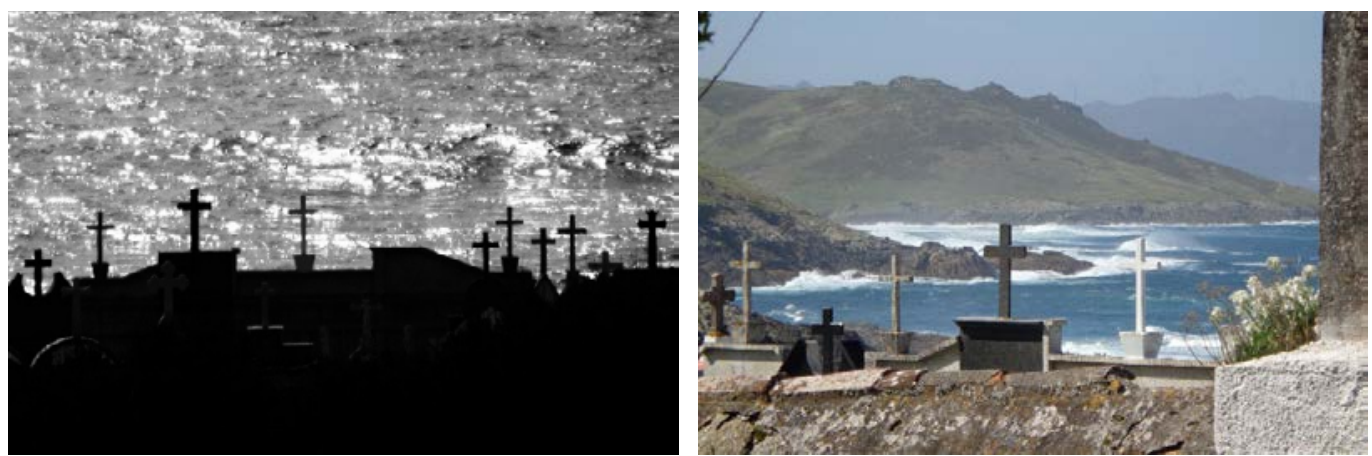

Fonte: (foto da esquerda- http://luisetemiravalles.blogspot.pt/2014/06/cementerio-de-laxe.html; foto da direita: autor)

Figura 6- Cemitério dos Ingleses (Foto 11) e o Cemitério de Santa Mariña-Camariñas (Foto 12)
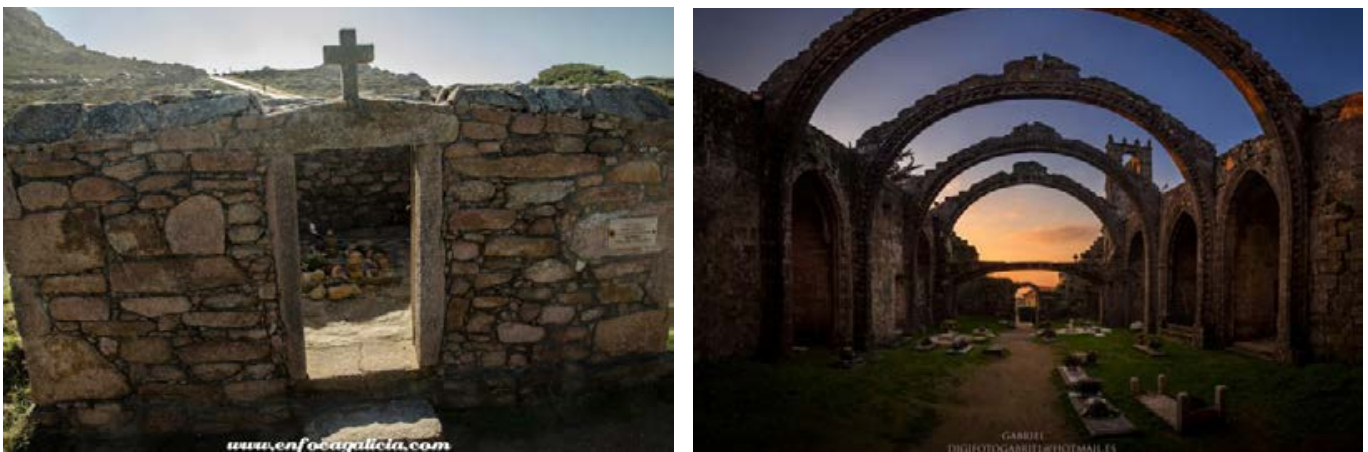

Fonte: (foto esquerda- http://enfocagalicia.com/cementerio-de-los-ingleses/; foto direita-https://500px.com/ gsm7000)

Figura 7 - Cruzes memoriais em Punta Roncudo (Fotos 13 e 14)
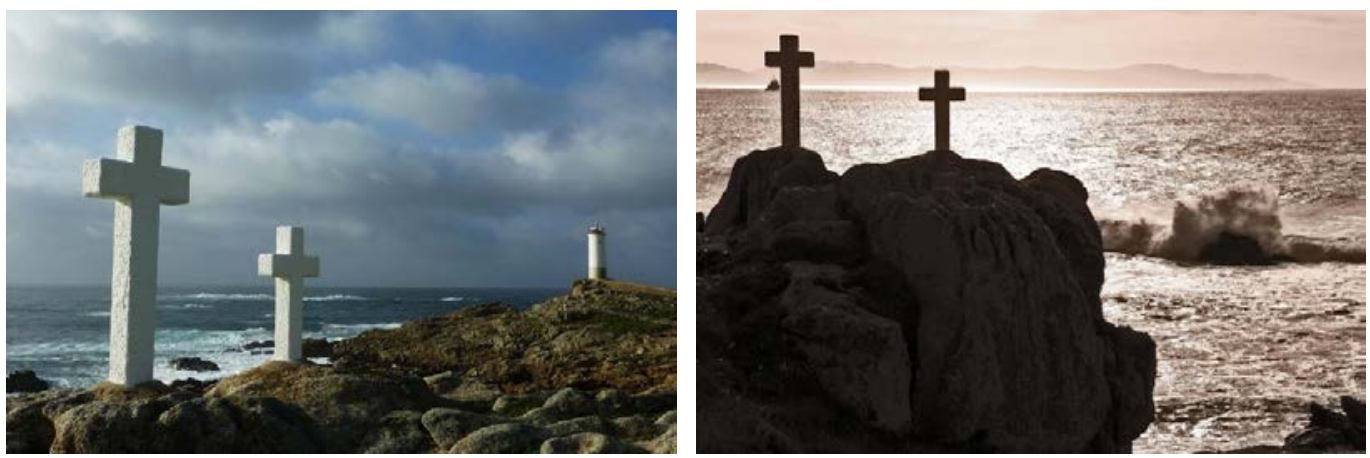

Fonte: (Foto esquerda: autor - Alicia Ferrer, publicada em https://www.facebook.com/photo.php?fbid=10 211098020112550\&set=p.10211098020112550\&type $=3 \&$ theater; foto direita- https://blog.cosasdemeiga. com/2014/05/13/las-cruces-del-mar-del-monte-roncudo/) 


\section{Figura 8 - Monstros marinhos: ex: Polvo - Corunha (Foto 15) e Sereia- Ilha Salvora (Foto 16).}
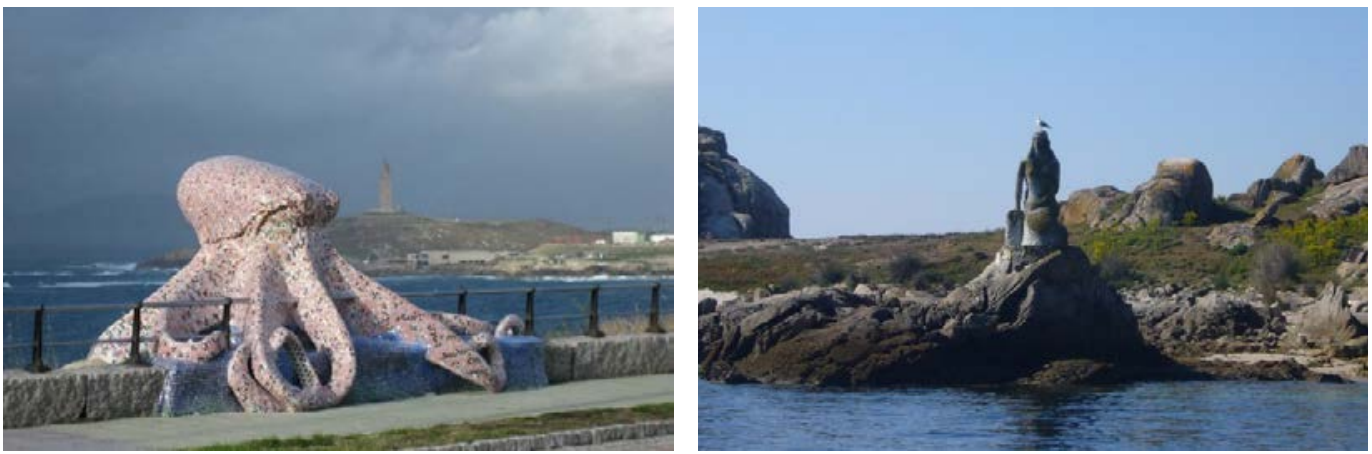

Fonte: (foto direita- http://www.panoramio.com/photo/4429602; foto esquerda- http://www.tripmondo.com/ spain/galicia/isla-de-salvora/)

Figura 9- Paisagem distópica dos filmes “Costa da Morte (Foto 17) e "Penúmbria" (Foto 18)
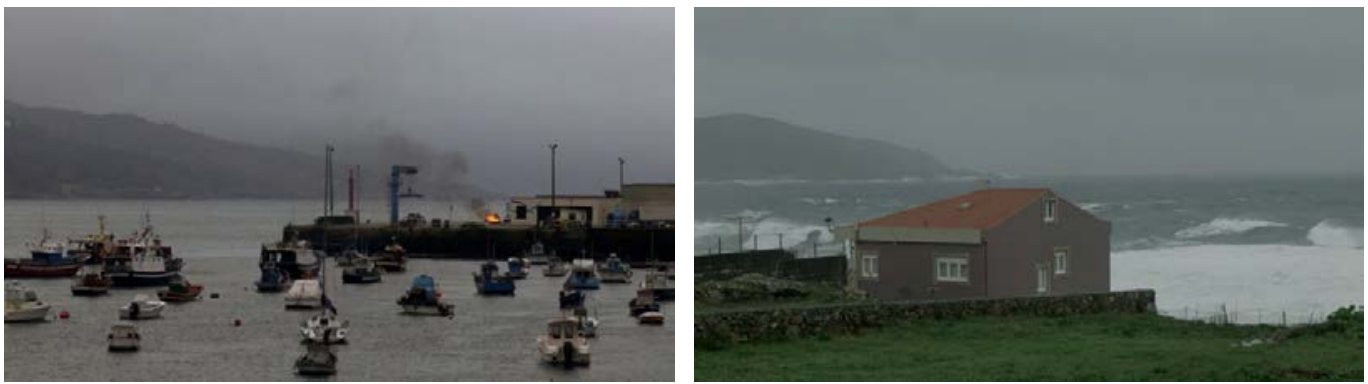

Fonte: Foto esquerda - http://loispatino.com/Costa-da-morte; Foto direita- http://www.eduardobrito.pt/ penumbria.html

Nas figuras 5 e 6, apresentam-se as fotos da categoria cemitérios, que constituem um destino tradicional do turismo negro: o cemitério de Laxe (fotos 9 e 10) que surge destacado no documentário da TVE "mas alla del fin del mundo", com um enquadramento cénico da morte, em que as cruzes contrastam na paisagem, beneficiando da localização privilegiada numa quota superior, numa falésia banhada pelo mar revolto. O cemitério dos ingleses (foto 11) e o cemitério de Santa Mariña (foto 12) estão, por sua vez, incluídos na Rota de Cemitérios com significado (http://www.significantcemeteries.org) devido ao seu passado histórico e patrimonial.

As cruzes memoriais ao longo da costa, assinalando os locais dos naufrágios, são também uma temática frequente nas fotos da costa da Morte (ver Figura 7) e, perpetuam esses acontecimentos na memória dos residentes locais, dando expressão ao conceito de santificação descrito na revisão de literatura na seção anterior.

$\mathrm{Na}$ Figura 8, por sua vez, apresentam-se dois exemplos dos seres marinhos reais ou mitológicos que frequentam esta região. Por um lado, o polvo, elemento tradicional da gastronomia galega e, por outro, o poder de sedução e sensualidade da sereia. Ainda recentemente, em outubro de 2016, foi avistada e fotografada nesta costa uma lula gigante ${ }^{3}$, também designada pelo nome legendário de Kraken, entre vários casos que dão suporte real a esta categoria.

O conceito de distopia está representado na Figura 9, onde se podem ver fotografias de dois cineastas (o galego Lois Patiño e o português Eduardo Brito), que procuraram capturar a identidade da Costa da Morte através da fotografia e do cinema. A distopia está também associada a outro fenómeno designado por "feísmo", que tem sido estudado por diversos autores de diferentes áreas em particular na arquitetura 
(Rego \& Costa, 2015). Este está associado à degradação da paisagem nos fins do século XX, motivada, entre outros fatores, pela depressão económica.

Finalmente, a última categoria relacionada com fenómenos celestes (Figura 10), que se podem observar nesta região e, que reforçam a importância geoestratégica dos "fins de terra", que proporcionam as condições ideais para a observação dos fenómenos astronómicos.

Figura - 10- Fenómenos celestes: Via Lactea (Foto 19) e alinhamento de planetas (Foto 20).
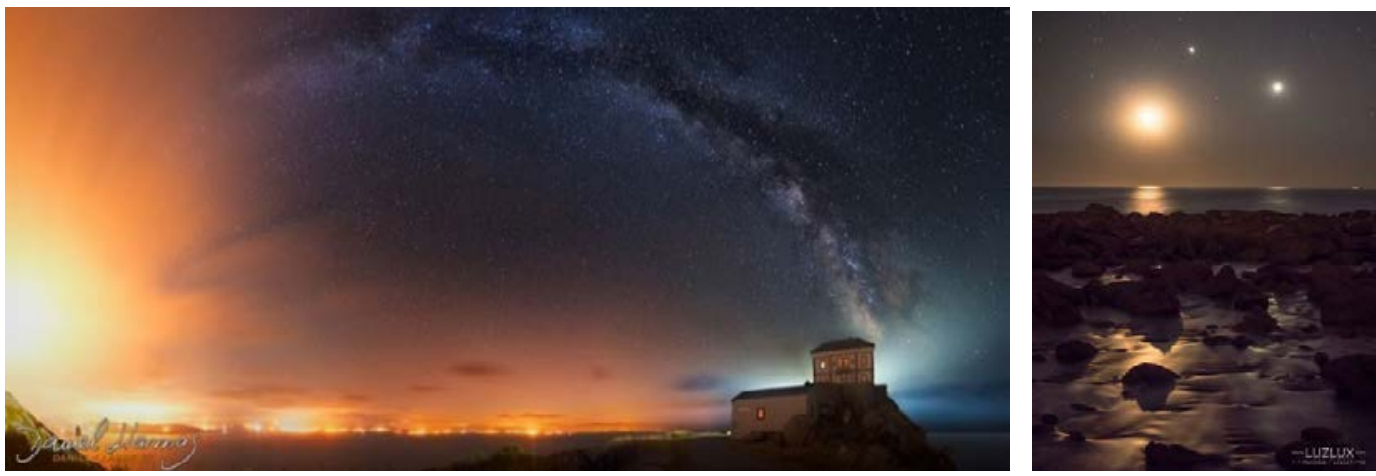

Foto esquerda - https://500px.com/daniel-llamas; Foto direita- https://apod.nasa.gov/apod/ap150624.html

\section{Conclusão e sugestões de investigações futuras}

O objetivo do estudo era demonstrar até que ponto uma fotografia pode ser uma representação da identidade de um lugar, contagiar emoções, simular/ emular experiências e motivar a visita ao destino. Reconhecendo a importância, como fator push, do fascínio (gaze) pela imagem, da perceção da autenticidade e da densidade psicológica de fotografias, documentários, livros, a observação direta e conteúdos digitais publicados na internet e redes sociais, foram propostos diversos elementos ou categorias de classificação de conteúdos latentes.

Para complementar esta categorização seria interessante validar a interpretação dos conteúdos em futuras investigações, nomeadamente através de grupos de discussão com a participação dos diversos stakeholders: turistas, operadores e residentes no destino.

\section{Bibliografia}

Belk, R.

2011. Examining markets, marketing, consumers, and society through documentary films. Journal of

Macromarketing, 31(4), 403-409.

Berger, A.

2004. Deconstructing travel: Cultural perspectives on tourism. Walnut Creek, CA: Altamira Press.

Berlyne, D.

1950. Novelty and curiosity as determinants of exploratory behavior. British Journal of Psychology, 41-68-80.

Blanco, J.

2014. 50 Faros de Galicia. Biblos.

Bouzas,P. \& Domelo, X.

2000. Mitos, ritos y leyendas de Galicia. Ediciones Martínez Roca.

Bryman, A.

2008. Social research methods. Oxford: Oxford University Press. 
Castro, A. \& Rodríguez, G.

2009. Turismo de desastres: aproximación a la explotación turística del desastre del Prestige en la Costa da Morte. Revista Galega de Economía, 18(2).ISSN 1132-2799.

Cela, C.J.

2001. Madeira de Buxo. Lisboa: Editorial Noticias.

Cohen, E.

1974. Who is a tourist?: A conceptual clarification. The Sociological Review, 22 (4), 527-555.

Cole, T.

1999. Selling the Holocaust. From Auschwitz to Schindler: How history is bought, packaged, and sold.

New York: Routledge.

Coplan, A.

2006. Catching characters' emotions: emotional contagion responses to narrative fan fiction. Film Studies, 8(Summer), 26-38.

Cortizo, F.

2016. Naufragios y crónica marítima de Galicia asta 1899. La Coruña: Cartamar.

Crouch, D., Jackson, R., \& Thompson, F.

2005. The media and the tourist imagination: Converging cultures. London: Routledge.

Debord, G.

1994. The society of spectacle. New York: Zone Books

Dempsey, J. V., \& Tucker, S. A.

1994. Using photo-interviewing as a tool for research and evaluation. Educational Technology, 34(4), 55-62.

Foley, M., \& Lennon, J. J.

1996. JFK and dark tourism: heart of darkness. Journal of International Heritage Studies, 2(4), 198-211.

Foote, K.

1997. Shadowed Ground: America's Landscapes of Violence and Tragedy. Austin TX: University of

Texas Press.

García, J.

2013. La leyenda de la Costa de la Muerte. Naufragios y faros como desencadenantes para la activación

de un patrimonio marítimo. SEMATA, Ciencias Sociais e Humanidades, 25, 257-290. ISSN 1137-9669.

Gordon, R. \& Cruz, J.

2002. Simulation theory. In L. Nadel(ed), Encyclopedia of Cognitive Science. Macmillan.

Hatfield, E., Cacioppo, J. T., \& Rapson, R. L.

1992. Primitive emotional contagion. In M. S. Clark (Ed.), Emotion and social behavior. Thousand

Oaks, CA: Sage.

Henderson, K. A.

1991. Dimensions of choice: A qualitative approach to recreation, parks, and leisure research (2nd ed.).

College park, PA: Venture Publishing.

Herrero, N.

2009. La atracción turística de un espacio mítico: peregrinación al cabo de Finisterra. Revista de Turismo y Patrimonio Cultural, 7 (2), 163-178.

Hosany, S., \& Prayag, G.

2013. Patterns of Tourists' Emotional Responses, Satisfaction, and Intention to Recommend. Journal of Business Research, 66(6), 730-737.

Hsu, C. \& Song, H.

2014. A Visual Analysis of Destinations in Travel Magazines. Journal of Travel \& Tourism Marketing, 31(2), 162-177.

Hsu, S., Dehuang, N., \& Woodside, A. G.

2009. Storytelling research of consumers' self-reports of urban tourism experiences in China. Journal of Business Research, 62(12), 1223-1254. 
Hunter, W. C.

2008. A typology of photographic representations for tourism: Depictions of groomed spaces. Tourism Management, 29(2), 354-365.

Hunter, W. C.

2010. Groomed spaces on Jeju Island: A typology of photographic representations for tourism. International Journal of Tourism Research, 12(6), 680-695.

Kelly, G.

1991. The Psychology or Personal Constructs, Volume 1. London: Routledge.

Kim, H., Stepchenkova, S.

2010. Effect of tourist photographs on attitudes towards destination: manifest and latent contente.

Tourism Management, 49, 29-41.

Kolbe, R. H., \& Burnett, M. S.

1991. Content-analysis research: An examination of applications with directives for improving research reliability and objectivity. Journal of Consumer Research, 18(2), 243-250.

Kozinets, R. V.

2010. Netnography: Doing ethnographic research online. Thousand Oaks: Sage.

Lee, T. \& Crompton, J.

1992. Measuring novelty seeking in tourism. Annals of Tourism Research, 19, 732-751.

Lennon, J., \& Foley, M.

2000. Dark tourism: The attraction of death and disaster. London: Continuum.

Lin, Y., Kerstetter, D., Nawijn, J. \& Mitas, O.

2014. Changes in emotions and their interactions with personality in a vacation context. Tourism Management, 40, 416-424.

Llodra-Riera, I., Martínez-Ruiz, M. Jimenez-Zarco, A. \& Izquierdo-Yusta, A.

2015. A multidimensional analysis of the information sources construct and its relevance for destination image formation. Tourism Management 48, 319-328.

Matteucci, X.

2013.Photo elicitation: Exploring tourist experiences with researcher-found images. Tourism Management, 35, 190-197.

Mayo, E. and Jarvis, L.

1981. The Psychology of Leisure Travel: Effective Marketing and Selling of Travel Services (Boston: CBI Publishing Co., Inc).

McIntosh. R. W. \& Goeldner, C.

1986. Tourism Principles, Practices, Philosophies. New York: John Wiley.

Min, K. S., Martin, D., \& Jung, J. M.

2013. Designing advertising campaigns for destinations with mixed images: Using visitor campaign goal messages to motivate visitors. Journal of Business Research, 66(6), 759-764.

Montgomery, K.C.

1952. Exploratory behavior and its relation to spontaneous alternation in a series of maze exposures. Journal of Comparative Physiology and Psychology, 45-50-57.

Moscardo, G., \& Ballantyne, R.

2008. Interpretation and attractions. In A. Fyall, B. Garrod, A. Leask, \& S. Wanhill (Eds.), Managing visitor attractions: New directions (pp. 237-252). Oxford: Butterworth-Heinemann.

Mouzo, R.

2014. Catálogo de naufragios. Costa da Morte-Galicia. Portada: donCLIC - Soluciones Tecnológicas.

Moutinho, L.

2000. Strategic Management in Tourism. CABI.

Özdemir, G.

2010. Photographs in brochures as the representations of induced image in the marketing of destinations: A case study of Istanbul. In P. M. Burns, J.A. Lester \& L. Bibbings (Eds.), Tourism and visual culture, Volume 2: Methods and cases (pp. 169-180). Cambridge, MA: CAB International.

Podoshen, J. S., \& Hunt, J. M.

2011. Equity restoration, the Holocaust and tourism of sacred sites. Tourism Management, 32(6), 1332-1342. 
Podoshen, J. S.

2013. Dark tourism motivations: simulation, emotional contagion and topographic comparison. Tourism Management, 35(1), 263-271.

Podoshen, J., Venkatesh, V., Wallin, J., Andrzejewski, S. \& Jin, Z.

2015. Dystopian dark tourism: An exploratory examination.Tourism Management, 1-13. http://dx.doi. org/10.1016/j.tourman.2015.05.002

Preston, S. D., \& deWaal, F. B. M. (2002). Empathy: its ultimate and proximate bases. Behavioral and Brain Science, 25, 1-72.

Rego, P. \& Costa, J.

2015. Guía de campo para la interpretación del feísmo en el paisaje gallego. Lugo: Horreum.

Reijnders, S.

2011. Stalking the count: Dracula, fandom and tourism. Annals of Tourism Research, 38(1), 231-248.

Ribeiro, N.

2009. Tourism Representation and Semiotics -Directions for Future Research. Cogitur: Journal of International Tourism Studies, 2, 7-14.

Riffe, D., Lacy, S., \& Fico, F. G.

2005. Analyzing media messages: Using quantitative content analysis in research. NJ: Lawrence Erlbaum Associates Publisher.

Rial, T.

2014. Visibilidad y reputación online de un destino turístico: caso práctico de a Costa da Morte. Trabajo fin de Master en Planificación y Gestión de Destinos y Nuevos Produtos Turísticos, Universidade da Coruña.

Rickly-Boyd, J.M.

2012. Authenticity \& Aura: A Benjaminian Approach to Tourism. Annals of Tourism Research, 39(1), 269-289.

Rojek, C.

1997. Indexing, dragging and the social construction of tourist sites. In C. Rojek, \& J. Urry (Eds.), Touring cultures: Transformations of travel and theory (pp. 52-74). London: Routledge.

Salazar, N.

2012. Tourism Imaginaries: a conceptual approach. Annals of Tourism Research, 39 (2), 863-882.

Sharpley, R.

2009. Shedding light on dark tourism: an introduction. In R. Sharpley, \& P. R. Stone (Eds.), The darker side of travel: The theory and practice of dark tourism (pp. 3-22). Tonawanda: Channel View.

Sharpley, R., \& Stone, P. R.

2009. (Re)presenting the macabre: interpretation, kitschification and authenticity. In R. Sharpley, \& P. R. Stone (Eds.), The darker side of travel: The theory and practice of dark tourism (pp. 109e128). Tonawanda: Channel View.

Stone, P. R.

2005. Dark tourism e and old concept in a new world. Tourism20, The Tourism Society, Quarter IV (25). Stone, P. R.

2006. A dark tourism spectrum: towards a typology of death and macabre related tourist sites, attractions and exhibitions. Tourism, 54(2), 145-160.

Stone, P. R.

2009. Making absent death present. In R. Sharpley, \& P. R. Stone (Eds.), The darker side of travel: The theory and practice of dark tourism (pp. 23-38). Tonawanda: Channel View.

Stone, P., \& Sharpley, R.

2008. Consuming dark tourism: a thanatological perspective. Annals of Tourism Research, 35(2), 574-595. 
Tarlow P. E.

2005. Dark Tourism: The appealing 'dark side' of tourism and more. In: Novelli M. (ed) Niche Tourism - Contemporary Issues, Trends and Cases (pp.47-58). Oxford: Butterworth Heinemann.

Tilden, F.

1977. Interpreting our heritage. Chapel Hill, NC: University of North Carolina Press.

Van House, N.

2009. Collocated photo sharing, story-telling, and the performance of self. International Journal Human-Computer Studies, 67, 1073-1086.

Xiang,Z. \& Gretzel,U.

2010. Role of social media in online travel information search. Tourism Management, 31(2): 179-188.

\section{NOTAS}

1 http://www.telegraph.co.uk/travel/galleries/Dark-tourism-sites-around-the-world/dark15/

2 A mini-série francesa Dolmen, que retrata de forma ficcionada este tipo de práticas na Bretanha francesa é um dos exemplos do interesse despertado por este tema.

3 http://www.20minutos.es/noticia/2861448/0/fotografian-ejemplar-calamar-gigante-costa-galicia/ 